\title{
Isolation and Identification of Arbuscular Mycorrhizal Fungi from Agricultural Fields of Vietnam
}

\author{
Zita Sasvári $^{1}$, Franco Magurno ${ }^{1}$, Dóra Galanics ${ }^{1}$, Tran Thi Nhu Hang ${ }^{2}$, Tran Thi Hong Ha ${ }^{2}$, \\ Nguyen Dinh Luyen ${ }^{2}$, Le Mai Huong ${ }^{2}$, Katalin Posta ${ }^{1}$ \\ ${ }^{1}$ Microbiology and Environmental Toxicology Group, Institute of Plant Protection, Szent István University, Gödöllő, Hungary; \\ ${ }^{2}$ Experimental Biology Laboratory, Institute of Natural Products Chemistry (INPC), Vietnam Academy of Science and Technology \\ (VAST), Hanoi, Vietnam. \\ Email: Posta.Katalin@mkk.szie.hu
}

Received September $10^{\text {th }}, 2012$; revised November $15^{\text {th }}, 2012$; accepted November $28^{\text {th }}, 2012$

\begin{abstract}
The rising claim for more environmental friendly and healthy agriculture is a strong incentive to find alternative strategies to replace the use of mineral fertilizer and pesticide. Arbuscular mycorrhizal fungi (AMF), a main component of soil microbiota, represent a promising tool as providers of key ecological services. The present work represented one of the first attempts to study, under a morphological and molecular point of view, the AMF communities associated to some strategic crops in Vietnam. The findings about the AMF morphotypes dominant in different crop systems could be a starting point for the development of well performing and adapted inocula suitable for the application in field.
\end{abstract}

Keywords: Arbuscular mycorrhizal Fungi; Spore Density; Vietnam Crops

\section{Introduction}

Plants, as traditionally component of the human diet, contain bioactive factors promoting physiological effects beyond nutrition with a positive impact on human health [1]. However at present the most part of crops in agricultural systems has been raised with significant input of mineral fertilizers and pesticides, resulting in a negative impact on the environment and a matter of concern for the consumers. A growing awareness of benefits from sustainable agriculture, as high-quality food, and more information on how food is produced, are pushing nowadays to a demand for reduced chemical inputs in agriculture. Among the initiatives towards improvement in low-input farming, the utilization of soil biota, providers of key ecological services, is one of the most promising strategies. Arbuscular mycorrhizal fungi, belonging to the phylum Glomeromycota, are a main component of soil microbiota and probably represent the most important terrestrial symbiosis $[2,3]$. Since about three decades these organisms have drawn the attention of researchers because of their ability to form intimate associations with $70 \%-90 \%$ of plant species [4], improving the mineral nutrients and water uptake in the plants [5] in exchange of photosynthetates [6]. Because of the wide diffusion AM symbiosis is believed to contribute significantly to global phosphate and carbon cycling and influence primary productivity in terrestrial ecosystems [3]. Further- more the establishment of this mutualistic association can stimulate, via activation of antioxidant, phenylpropanoid and carotenoid pathways [7], the synthesis of plant secondary metabolites which are important for increased plant tolerance to abiotic and biotic stresses $[8,9]$ or beneficial to human health through their antioxidant activity $[10,11]$. In recent years, much effort has been paid to obtain suitable formulations for AM fungal inocula and appropriate ways for their application to the field [12]. The development of inocula based on AM fungi has to take in account the adaptation ability in a contest of indigenous AMF populations. The native communities in fact show generally a better fitness in the environmental conditions of their eco/agro-system in comparison to foreign species [13] and this could compromise the efficiency on AMF inocula application. In addition, as AM fungal inoculants are most often of foreign origin, attention has to be paid about the possibility of invasive spreading after release to the field and further negative ecological consequences [14]. The study and selection of isolates from endemic AMF communities could represent an alternative to the use of not native organisms, also in the aim of restocking those soils with a microflora depleted by intensive agricultural practices.

With the present work we may extend the knowledge of native AMF population associated to typical Vietnamese crops. The AM propagules in the rhizosphere 
were investigated by both a morphological and molecular approach, and the dominant strains isolated in pure cultures.

\section{Materials and Methods}

\subsection{Study Site and Sampling}

Rhizosphere soil and roots of rice (Oryza sativa), maize (Zea mays), peanut (Arachis hypogaea), croton (Croton tonkinensis Gagnep) and tomato (Lycopersicon esculentum) were collected at June 2011 at Bắc Ninh and Hà Nội provinces in Vietnam. In rice seedlings started in seedling beds and, after 30 to 50 days, were transplanted by hand to the fields, which had been flooded by rain or river water. During the growing season, irrigation was maintained by dike-controlled canals or by hand watering. The fields were allowed to drain before cutting. Additional information about the soil characteristic and time of cultivation are provided in Table 1.

\subsection{Spore Abundance}

AMF spores were isolated from $50 \mathrm{~g}$ air-dried soil samples by wet sieving [15] through 200 and $30 \mu \mathrm{m}$ sieves, followed by sucrose gradient centrifugation [16]. After centrifugation, spores and spore clusters were transferred into Petri dishes and counted in three replications under stereomicroscope at $100 \times$ magnification. Spore abundance was expressed as the number of AMF spores per gram soil.

\subsection{Morphological Analyses}

Spores were analyzed under stereomicroscope at $100 \times$ magnification and divided in groups in relation to morphological characteristics as shape, size, colour, presence of structures like sporiferous saccule, subtending hypha.

\subsection{Trap Cultures}

Part of the soil sampled was used to set up trap cultures, mixed with sand and black peat $(1: 1: 1)$.

The aims of the cultures were to maintain a living collection of the organisms in study and obtain fresh spores to set up monospore cultures. Maize was chosen as symbiotic partner, because of its high mycorrhizal dependency. Low phosphate $(32 \mu \mathrm{M})$ Long Ashton solution was used for watering.

\subsection{DNA Extraction and Amplification}

Eight spores from the most represented groups were chosen and the DNA was extracted from single spores. Each spore was crushed under stereomicroscope in $10 \mu \mathrm{l}$ volume $(5 \mu \mathrm{l} 5 \times$ GoTaq PCR buffer and $5 \mu$ distillated water) and then boiled for 15 '. After 5 ' centrifugation at $14 \mathrm{Krpm}, 2 \mu \mathrm{l}$ of supernatant were used as template for the PCR. To enhance the PCR yield NS1 (5'-GTA GTC ATA TGC TTG TCT C-3') and NS4 (5'-CTT CCG TCA ATT CCT TTA AG-3') universal primers [17] were used in the first amplification followed by nested amplification with Lee primers pair AML1 (5'-ATC AAC TTT CGA TGG TAGGAT AGA-3') and AML2 (5'-GAA CCC AAA CAC TTT GGT TTC C-3') [18]. PCR amplifications were performed using GoTaq polymerase (Promega) in $20 \mu \mathrm{l}$ final volume mixture following the thermal profile described for each couple of primers. PCR products of the expected size $(\sim 800 \mathrm{bp})$ were then checked and purified from agarose gel with GFX PCR DNA and Gel Band Purification Kit (GE Healthcare, Amersham Biosciences, Amersham, UK).

\subsection{Cloning and Restriction Analyses}

Purified fragments were cloned into $\mathrm{pGEM}^{\circledR}-\mathrm{T}$ Easy Vector (Promega, Madison, WI, USA) and transformed into Escherichia coli DH5 $\alpha$. Positive transformants were checked by PCR for the presence and size of the insert.

Four clones for each transformation were characterized by restriction pattern, cutting the PCR fragment with HinfI (Fermentas) for $3 \mathrm{~h}$ at $37^{\circ} \mathrm{C}$. Restriction products

Table 1. Summary of the informations related to the crops in study: sampling place, cultivation period and characteristics of the rhizosphere soil.

\begin{tabular}{|c|c|c|c|c|c|c|c|}
\hline \multirow[b]{2}{*}{ Crop } & \multirow[b]{2}{*}{ Sampling place } & \multicolumn{3}{|c|}{ Cultivation time } & \multirow{2}{*}{$\begin{array}{c}\text { Moisture } \\
\%\end{array}$} & \multirow[b]{2}{*}{$\mathrm{pH}$} & \multirow[b]{2}{*}{ Soil type } \\
\hline & & Spring & $\begin{array}{l}\text { Summer } \\
\text { autumn }\end{array}$ & $\begin{array}{c}\text { Autumn } \\
\text { winter }\end{array}$ & & & \\
\hline Rice & Dong Anh, HaNoi & $\begin{array}{c}\text { November } \\
\text { January }\end{array}$ & $\begin{array}{l}\text { June } \\
\text { July }\end{array}$ & & 100 & $6-6.5$ & Acrisol \\
\hline Tomato & TrauQuy, Ha Noi & $\begin{array}{c}\text { December } \\
\text { January }\end{array}$ & $\begin{array}{l}\text { June } \\
\text { July }\end{array}$ & $\begin{array}{c}\text { October } \\
\text { November }\end{array}$ & $65-70$ & $6-6.5$ & Alluvial soil \\
\hline Peanut & BacNinh & $\begin{array}{l}\text { January } \\
\text { February }\end{array}$ & June & August September & $70-80$ & $5.5-7$ & Clay with sand \\
\hline Maize & BacNinh & $\begin{array}{c}\text { December } \\
\text { January }\end{array}$ & May June & August September & $65-70$ & $6-7$ & Alluvial soil \\
\hline
\end{tabular}


were analyzed after 30 ' run in $1 \times$ TBE agarose gel $2.5 \%$.

Plasmids from clones representative of each restriction profile were extracted with the Wizard ${ }^{\circledR}$ Plus SV Minipreps DNA Purification System Kit (Promega, Madison, WI, USA) and sent for sequencing to the BIOMI Kft., Gödöllő, Hungary.

\subsection{Editing and Phylogenetic Analyses}

Sequence similarities were determined by BLASTn provided by GenBank. Only sequences belonging to Glomeromycota were selected for the subsequent analyses and the others were discarded. Sequences editing was performed manually using MEGA 4.0 [19] and Chromas Lite 2.01. The sequences were deposited at the National Centre for Biotechnology Information (NCBI) GenBank with accession numbers KC182580-KC182586.

Sequences were aligned by MUSCLE with those identified by the BLASTn search and with reference sequences of the major groups of Glomeromycota. MEGA 4.0 software assessing Kimura- $2 \mathrm{p}$ model as distance method and 1000 replicates of non-parametric bootstrapping was used to construct a Neighbor-joining (NJ) consensus tree.

\subsection{Statistical Analyses}

The data from spores number assessment were analyzed using R software package version 2.13.2

(www.R-project.org). General log-linear modelling was carried out to estimate correlations among different crops at $\mathrm{p}=0.05$ significance level.

\section{Result and Discussion}

Spore abundance in the rhizosphere of the different crops analyzed is shown in the Figure 1. Tomato and peanut owned the highest number of spores per gram (11.32 \pm 1.00 ) without significant difference, followed by croton $(7.12 \pm 0.65)$, maize $(5.15 \pm 0.13)$ and rice $(2.61 \pm 1.41)$. In general results about spore abundance were found to be in agreement with those from other studies on arable

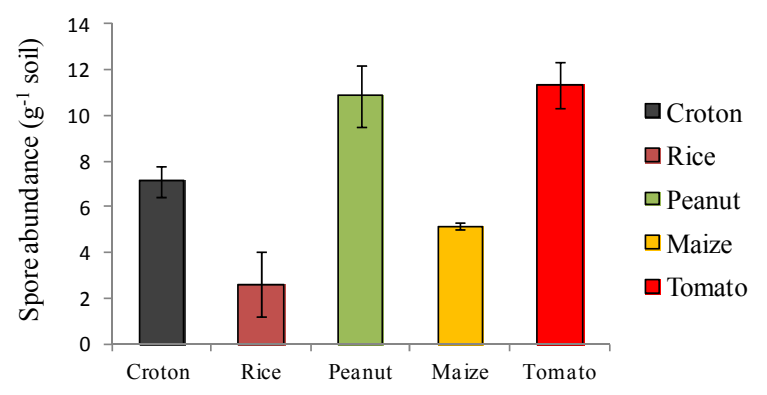

Figure 1. Spore abundance as number of spores per gram of soil. Each value was calculated as the mean of three replicates. The bars represent the $95 \%$ confidence level for each measure. lands with intermediate or high input [20]. This could be due to the intensive utilization of the soil with 2 - 3 harvesting per year. Rice appeared to be the poorest crop as AMF potential soil inoculum. These data could find an explanation in the flooding regime the crop was subjected to. As reported in several publications flooding has a negative impact both on root colonization and spore abundance in the soil, probably to the anoxic environment $[21,22]$. Other studies showed that AMF can colonize roots of aquatic plants depending on the affiliation to monocots or dicots species [23]. Monocot species are generally not mycorrhizal. The higher proportion of aerenchyma in the monocot roots, through a high $\mathrm{O}_{2}$ and $\mathrm{H}^{+}$release into soil, may play a role in facilitating $\mathrm{P}$ uptake and this increased $\mathrm{P}$ uptake would be responsible for a decrease in colonization.

Despite an oxic environment suitable for AMF growth, the root colonization would be depressed with a conesquent reduction of the presence of spores in the soil. Also in croton, the spore density was found low despite this species was perennial and no soil disturbance occurred. Content of nutrients and $\mathrm{pH}$ didn't differ significantly from the soil of the tomato, maize and peanut. Only the moisture percentage of the soil was found about half of that measured for tomato, maize and peanut rhizosphere. Soil moisture could affect AMF sporulation [24] with a different effect depending on the fungal species [25].

Spores isolated from soil were divided in groups on the basis of morphological characteristics. In rice and peanut the dominant type was characterized by yellowbrown spores, mostly globose, with a size ranging from $70-100 \mu \mathrm{m}$ and in some case with a hyaline sporiferous saccule. In croton dominant spore type was subhyaline, globose, 70 - $100 \mu \mathrm{m}$ size range and with a hyaline sporiferous saccule. In maize dominant spore type was orange-brown, subglobose, $120-190 \mu \mathrm{m}$ size range. In tomato the three types mentioned above were detected, also if the third type only occasionally.

Due to the little amount of DNA per single spores about $50 \%$ of PCR amplifications were successful. In the RFLP analyses every group of spores resulted characterized by a single restriction profile. When, in a single event of transformation, a clone showed a different profile from the other clones, it was considered as a contamination and discarded. Totally three restriction profiles were found (Figure 2), one shared by rice, peanut and tomato (RP1), one shared by croton and tomato (RP2) and one shared by maize and tomato (RP3). Overall seven clones were sequenced, one for each restriction profile found in each crop system. In the phylogenetic tree the sequences with the same restriction pattern clustered together (Figure 3). The phylotypes associated to the profile RP1 (rice, peanut, tomato) clustered together with the species Acaulospora longula, RP2 (croton and 
tomato) with an uncultured Acaulospora while RP3 (maize and tomato) with Funneliformis mosseae. The genus Acaulospora, generally is not frequent in the arable lands [20,26], because not disturbance tolerant. In our work it appeared o be well represented, also in a par-

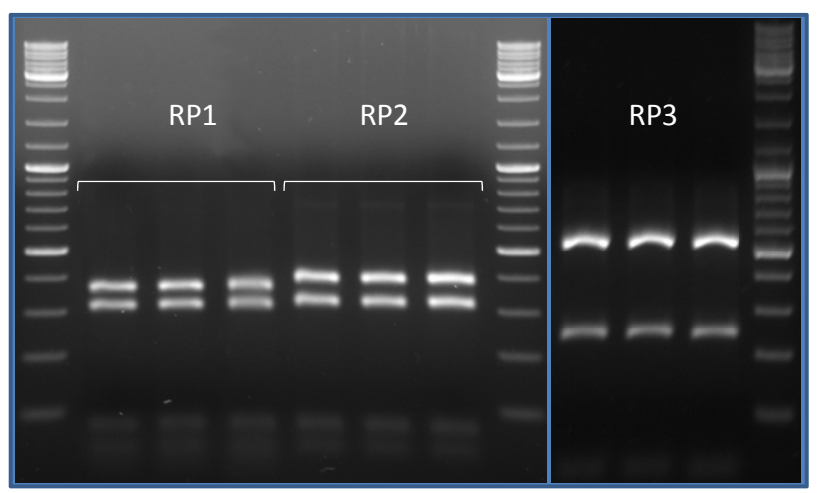

Figure 2. Comparison of the RFLP profiles associated to the morphotypes isolated. The products of enzymatic restrictions were run in a high resolution agarose gel (2.5\%) with a 100 bp ladder. RP1 (rice, peanut, tomato) and RP2 (croton and tomato) showed similar patterns but except for the heaviest band equal to 400 bp in RP2 and slightly lower in RP1. RP3 (maize and tomato) differed clearly from the other patterns. ticular condition like rice grown in flooding regime, where members of the family Glomeraceae (Funneliformis, Rhizophagus ...) were expected [22]. The uncultured Acaulospora sequence phylogenetically related to RP2 was obtained in an unpublished study on rice cultivation in Thailand. In the BLASTn analyses as well as in the phylogenetically analyses no morphospecies belonging to the genus Acaulospora were found related to such sequence, so the presence of a species, at the moment morphologically not characterized, endemic of the Indochinese peninsula, is plausible.

Spores likely related to Funneliformis mosseae were found the dominant type only in the rhizosphere of maize.

In conclusion this work represented one of the first attempts to study, under a morphological and molecular point of view, the AMF communities associated to some strategic crops in Vietnam. The resulted obtained should extend the knowledge of native AMF population in the perspective of selection and development well performing and adapted inocula.

\section{Acknowledgements}

The research was supported by the TÉT-10-1-2011-0648

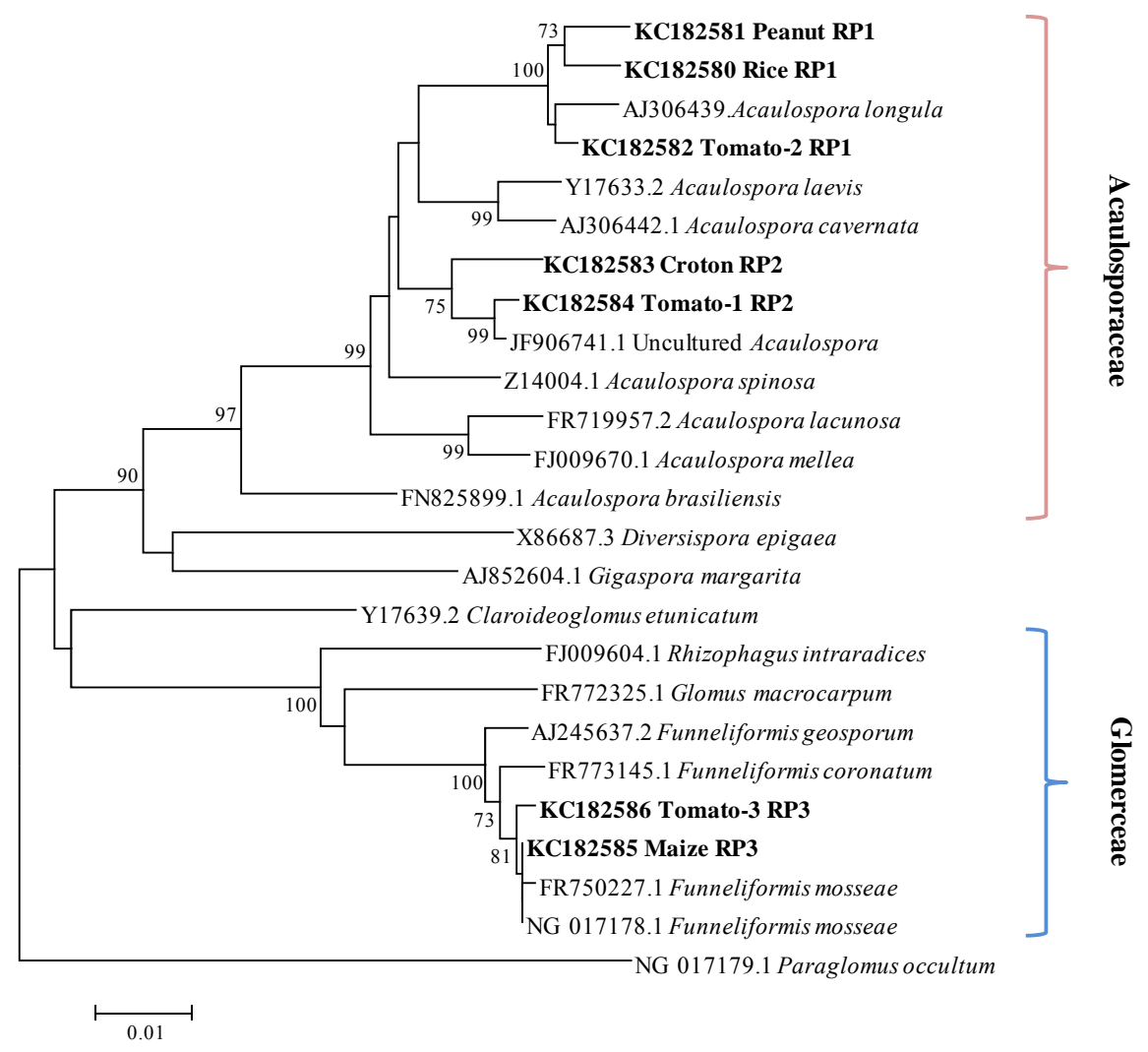

Figure 3. Neighbor-joining phylogenetic tree showing the relationships among the AML1/AML2 rDNA sequences from the morphotype isolated and reference sequences from GenBank. Numbers next the nodes indicate the bootstrap values (above $70 \%, 1000$ replicates) of the neighbor-joining analysis. Paraglomus occultum NG 017179.1 was used to root the tree. 
"Hungarian-Vietnamese intergovernmental cooperation program", by 53/2011/ HĐ-NĐT (MOST-VietNam) and by the TÁMOP 4.2.2/B-10/1-2010-011 "Development of a complex educational assistance/support system for talented students and prospective researchers at the Szent István University” project.

\section{REFERENCES}

[1] F. C. Stintzing and R. Carle, "Functional Properties of Anthocyanins and Betalains in Plants, Food, and in Human Nutrition," Trends in Food Science \& Technology, Vol. 15, No. 1, 2004, pp. 19-38. doi:10.1016/j.tifs.2003.07.004

[2] P. Jeffries, S. Gianinazzi, S. Perotto, K. Turnau and J. M. Barea, "The Contribution of Arbuscular Mycorrhizal Fungi in Sustainable Maintenance of Plant Health and Soil Fertility," Biology and Fertility of Soils, Vol. 37, No. 1, 2003, pp. 1-16.

[3] A. H. Fitter, "Darkness Visible: Reflections on Underground Ecology," Journal of Ecology, Vol. 93, 2005, pp. 231-243.

[4] S. E. Smith and D. J. Read, "Mycorrhizal Symbiosis," 3rd Edition, Academic Press, London, 2008.

[5] R. D. Finlay, "Ecological Aspects of Mycorrhizal Symbiosis: With Special Emphasis on the Functional Diversity of Interactions Involving the Extraradical Mycelium," Journal of Experimental Botany, Vol. 59, No. 5, 2008, pp. 1115-1126. doi:10.1093/jxb/ern059

[6] B. Bago, P. E. Pfeffer, J. Abubaker, J. Jun, J. W. Allen, J. Brouillette, D. D. Douds, P. J. Lammers, Y. B. ShacharHill, et al., "Carbon Export from Arbuscular Mycorrhizal Roots Involves the Translocation of Carbohydrate as Well as Lipid," Plant Physiology, Vol. 131, No. 3, 2003, pp. 1496-1507. doi:10.1104/pp.102.007765

[7] M. Baslam, I. Garmendia and N. Goicoechea, "Arbuscular Mycorrhizal Fungi (AMF) Improved Growth and Nutritional Quality of Greenhouse-Grown Lettuce," Journal of Agricultural and Food Chemistry, Vol. 59, No. 10, 2011, pp. 5504-5515. doi:10.1021/jf200501c

[8] B. A. Sikes, C. Cottenie and J. N. Klironomos, "Plant and Fungal Identity Determines Pathogen Protection of Plant Roots by Arbuscular Mycorrhizas," Journal of Ecology, Vol. 97, No. 6, 2009, pp. 1274-1280. doi:10.1111/j.1365-2745.2009.01557.x

[9] M. Miransari, "Contribution of Arbuscular Mycorrhizal Symbiosis to Plant Growth under Different Types of Soil Stress," Plant Biology, Vol. 12, 2010, pp. 563-569.

[10] N. P. Seeram, "Berry Fruits: Compositional Elements, Biochemical Activities, and the Impact of Their Intake on Human Health, Performance, and Disease," Journal of Agricultural and Food Chemistry, Vol. 56, No. 3, 2008, pp. 627-629. doi:10.1021/jf071988k

[11] J. Albrechtova, A. Latr, L. Nedorost, R. Pokluda, K. Posta and M. Vosatka, "Dual Inoculation with Mycorrhizal and Saprotrophic Fungi Applicable in Sustainable Cultivation Improves the Yield and Nutritive Value of
Onion," The Scientific World Journal, 2012, Article ID 374091.

[12] S. Gianinazzi and M. Vosatka, "Inoculum of Arbuscular mycorrhizal Fungi for Production Systems, Science Meets Business," Canadian Journal of Botany, Vol. 82, No. 8, 2004, pp. 1264-1271. doi:10.1139/b04-072

[13] I. Hernádi, Z. Sasvári, J. Albrechtová, M. Vosátka and K. Posta, "Arbuscular Mycorrhizal Inoculants Increase Yield of Spice Pepper and Affects Indigenous Fungal Community in the Field," HortScience, Vol. 47, No. 5, 2012, pp. 603-606.

[14] M. W. Schwartz, J. D. Hoeksema, C. A. Gehring, N. C. Johnson, J. N. Klironomos, L. K. Abbott and A. Pringle, "The Promise and the Potential Consequences of the Global Transport of Mycorrhizal Fungal Inoculum," Ecology Letters, Vol. 9, 2006, pp. 501-515. doi:10.1111/j.1461-0248.2006.00910.x

[15] J. W. Gerdemann and T. H. Nicolson, "Spores of Mycorrhizal Endogone Species Extracted from Soil by Wet Sieving and Decanting," Transactions of the British Mycological Society, Vol. 46, No. 2, 1963, pp. 235-244. doi:10.1016/S0007-1536(63)80079-0

[16] D. C. Ianson and M. F. Allen, "The Effects of Soil Texture on Extraction of Vesicular-Arbuscular Mycorrhizal Fungal Spores from Arid Sites," Mycologia, Vol. 78, No. 2, 1986, pp. 164-168. doi:10.2307/3793161

[17] T. J. White, T. Bruns, S. Lee and J. Taylor, “Amplification and Direct Sequencing of Fungal Ribosomal RNA Genes For Phylogenetics," In: M. A. Innis, D. H. Gelfand, J. J. Sninsky and T. J. White, Eds., PCR Protocols: A Guide to Methods and Application, Academic, San Diego, 1990, pp. 315-322.

[18] J. Lee, S. Lee and J. P. Young, "Improved PCR Primers for the Detection and Identification of Arbuscular mycorrhizal Fungi," FEMS Microbiology Ecology, Vol. 65, No. 2, 2008, pp. 339-349. doi:10.1111/j.1574-6941.2008.00531.x

[19] K. Tamura, J. Dudley, M. Nei and S. Kumar, "MEGA4: Molecular Evolutionary Genetics Analysis (MEGA) Software Version 4.0," Molecular Biology and Evolution, Vol. 24, 2007, pp. 1596-1599. doi:10.1093/molbev/msm092

[20] F. Oehl, E. Sieverding, K. Ineichen, P. Mader, T. Boller and A. Wiemken, "Impact of Land Use Intensity on the Species Diversity of Arbuscular Mycorrhizal Fungi in Agroecosystems of Central Europe," Applied and Environmental Microbiology, Vol. 69, No. 5, 2003, pp. 28162824. doi:10.1128/AEM.69.5.2816-2824.2003

[21] W. Wangiyana, P. S. Cornish and E. C. Morris, "Arbuscular Mycorrhizal Fungi Dynamics in Contrasting Cropping Systems on Vertisol and Regosol Soils of Lombok, Indonesia," Experimental Agriculture, Vol. 42, No. 4, 2006, pp. 427-439. doi:10.1017/S0014479706003826

[22] E. Lumini, M. Vallino, M. M. Alguacil, M. Romani and V. Bianciotto, "Different Farming and Water Regimes in Italian Rice Fields Affect Arbuscular mycorrhizal Fungal Soil Communities," Ecological Applications, Vol. 21, No. 5, 2011, pp. 1696-1707. doi:10.1890/10-1542.1 
[23] W. K. Cornwell, B. L. Bedford and C. T. Chapin, "Occurrence of Arbuscular mycorrhizal Fungi in a PhosphorusPoor Wetland and Mycorrhizal Response to Phosphorus Fertilization," American Journal of Botany, Vol. 88, No. 10, 2001, pp. 1824-1829. doi:10.2307/3558359

[24] A. Brown and C. Bledsoe, "Spatial and Temporal Dynamics of Mycorrhizas in Jaumea Carnosa, a Tidal Saltmarsh Holophyte," Journal of Ecology, Vol. 84, 1996, pp. 703-715. doi: $10.2307 / 2261333$

[25] S. P. Miller and J. D. Bever, "Distribution of Arbuscular mycorrhizal Fungi in Stands of the Wetland Grass Panicum hemitomon along a Wide Hydrologic Gradient," Oecologia, Vol. 119, 1999, pp. 586-592. doi:10.1007/s004420050823

[26] M. M. Alguacil, E. Lumini, A. Roldán, J. R. SalinasGarcía, P. Bonfante and V. Bianciotto, "The Impact of Tillage Practices on Arbuscular Mycorrhizal Fungal Diversity in Subtropical Crops," Ecological Applications, Vol. 18, No. 2, 2008, pp. 527-536.

doi:10.1890/07-0521.1 